\title{
REFLEXÕES SOBRE O ESTADO A PARTIR DE DELEUZE E GUATTARI: A MICROPOLÍTICA-EM-NÓS
}

\author{
Reflections about State of starting Deleuze and Guattari: The Micropolitics-in-Us \\ Patrícia Marciano de Assis*
}

\begin{abstract}
Resumo: O objetivo desse artigo é tecer reflexões sobre a concepção de Estado presente nas leituras de algumas obras de Gilles Deleuze e Félix Guattari, bem como ressaltar suas contribuições para pensar a história. Metodologicamente analisamos alguns textos dos livros "O Anti-Édipo" e "Mil Platôs", principalmente seu quinto volume, bem como operamos um diálogo constante com a bibliografia. A escolha de tais textos foi realizada com base em uma pesquisa qualitativa e exploratória inicial, feita a partir das obras escritas em conjunto por ambos os autores, usada para identificar a abordagem histórica proposta por eles e, em seguida, o lugar do Estado nessa formulação. Ancorada em seu pensamento da diferença, vislumbramos a possibilidade de pensar sobre a construção do Estado sem cair no estruturalismo ou num psicologismo (sobretudo, a versão do familismo), apenas acompanhando seu modo de funcionamento e seus agenciamentos, estando sempre atentos ao pensamento da diferença proposto por eles e nas possibilidades aventadas pela ideia de micropolítica.
\end{abstract}

Palavras-chave: Estado, Micropolítica, Agenciamento.

\begin{abstract}
The purpose of this article is to make reflections about State's conception present in the readings of some works of Gilles Deleuze and Félix Guattari, as well as to highlight their contributions to think about history. Methodologically we analyze some texts of the books "The Anti-Oedipus" and "Thousand Plateaus", mainly its fifth volume, as well as we operate a constant dialogue with the bibliography. The choice of such texts was made on the basis of an initial qualitative and exploratory research, made from the works written jointly by both authors, used to identify the historical approach proposed by them and then the place of the State in that formulation. Anchored in her thinking about difference, we envisage the possibility of thinking about the construction of the State without falling into structuralism or a psychologism (especially the version of familism), only following its mode of operation and its assemblages, being always attentive to the thought of difference proposed by them and in the possibilities proposed by the idea of micropolitics.
\end{abstract}

Keywords: State, Micropolitics, Agency.

O objetivo desse artigo $^{1}$ é tecer algumas reflexões sobre a concepção de Estado a partir das obras de Gilles Deleuze e Félix Guattari, bem como ressaltar como seu pensamento pode contribuir para o trabalho do historiador. A metodologia utilizada foi uma análise exploratória inicial das obras escritas em conjunto por ambos os autores, a saber: "O Anti-Édipo", "Mil

\footnotetext{
* Possui Graduação em História (UECE, 2013), Especialização em História do Brasil (UVA, 2016) e Mestrado em História e Culturas (UECE, 2016). Atualmente é doutoranda em História pelo Programa de Pós-Graduação em História da Universidade Federal de Pernambuco (UFPE, 2017).

${ }^{1}$ Texto apresentado na disciplina "Tópico Especial em Teoria da História e Historiografia - O corpo-fluxo da história: para uma introdução ao pensamento sobre a história de Gilles Deleuze e Félix Guattari”, ministrada pelo professor Durval Muniz de Albuquerque Júnior, no Programa de Pós-Graduação em História da Universidade Federal de Pernambuco.
} 
Platôs", "Kafka" e "O que é filosofia?", bem como a seleção daquelas que melhor atendiam aos nossos propósitos. Dada à recorrência das discussões acerca da história e do Estado, e das possibilidades de sistematização das ideias e conceitos, analisamos qualitativamente os textos dos dois primeiros livros, principalmente o quinto volume de "Mil Platôs", excluindo os dois últimos, por tratarem mais diretamente de questões ligadas a literatura e ao pensamento filosófico $^{3}$, respectivamente. Ademais, operamos um diálogo constante com a bibliografia nas reflexões aqui propostas.

A questão que permeia este artigo é entender não só como podemos pensar teoricamente os diferentes processos de construção e organização das formações sociais a partir desses autores, mas como seu pensamento acerca do modo de funcionamento do Estado Moderno pode auxiliar os historiadores a repensar sua maneira de produzir conhecimento. Para tanto, dividimos o artigo em duas partes, onde localizamos a leitura que fazem da história da humanidade, a partir de seu exercício conjunto de pensar a diferença; e, em seguida, como constroem uma concepção de Estado considerando a multiplicidade e o caráter contingencial dos processos históricos.

Desta feita, é importante salientar que a nossa preocupação com essa temática está ligada aos questionamentos levantados acerca da ideia de Estado presente na historiografia e nas possibilidades de seguir caminhos outros que não os convencionais, especificamente, a possibilidade de pensar sobre a construção do Estado, sem cair no estruturalismo ou num psicologismo (sobretudo, a versão do familismo), apenas acompanhando seu modo de funcionamento e seus agenciamentos, estando sempre atentos ao pensamento da diferença proposto por eles e nas possibilidades aventadas pela ideia de micropolítica.

\footnotetext{
${ }^{2}$ DELEUZE, Gilles; GUATTARI, Félix. $O$ anti-Édipo: capitalismo e esquizofrenia $1.2^{\mathrm{a}}$ ed. Trad. Luiz B. L. Orlandi. São Paulo: Editora 34, 2011a; Mil platôs: capitalismo e esquizofrenia 2. vol. 5. 2a ed. Trad. Peter Pál Pelbart e Janice Caiafa. São Paulo: Editora 34, 2012c. Kafka: por uma literatura menor. Trad. Rafael Godinho. Rio de Janeiro: Assírio \& Alvim, 2003. O que é filosofia? Trad. Bento Prado Jr. e Alberto Alonso Muñoz. Rio de Janeiro: Ed. 34, 1992.

${ }^{3}$ Não entramos aqui nas distinções que eles estabelecem entre ciência e filosofia, apesar de serem elementos importantes para compreender as diferenças entre esses dois campos e pensar o lugar da história nessa discussão. Por exemplo, com relação a forma de cortar o caos, a filosofia se preocupa em conciliar a garantia de uma consistência do virtual e a preservação das velocidades infinitas na criação do conceito, enquanto, no sentido contrário, a ciência renuncia ao infinito e a velocidade para ganhar um plano referência que seja capaz de atualizar o virtual caótico; já na perspectiva temporal, apesar de também não se satisfazer com a ideia de uma sucessão linear, ao invés de exprimir o antes e o depois em termos de superposições, como o tempo estratigráfico da filosofia, a ciência trabalha com o desdobramento do tempo serial, ramificado, em que as bifurcações e rupturas por vir estão sempre designadas pelo precedente. Cf. DELEUZE, Gilles; GUATTARI, Félix. O que é filosofia?. Nos dois casos, a história está mais ligada ao modo de fazer da ciência, embora haja toda uma discussão sobre seu caráter científico e o peso dado a narrativa, então a questão teórica que pode ser levantada é em que medida o pensamento filosófico dos dois autores podem ser exercitado no fazer historiográfico, sem deixar de cumprir os critérios que lhes são inerentes. Sem respostas consistentes, optamos por acompanhar e considerar as ideias e críticas feitas para repensar nosso objeto ou, especificamente, o texto desta disciplina.
} 


\section{LEITURA DA HISTÓRIA DA HUMANIDADE: ENTRE A FILOSOFIA DA DIFERENÇA E A CRÍTICA A REPRESENTAÇÃO}

Antes de entrar na discussão aqui proposta, faz-se necessário tecer alguns comentários acerca dos exercícios filosóficos de pensar o conhecimento de ambos os autores. De acordo com Machado ${ }^{4}$, as diversas leituras, obras e temas trabalhados por Deleuze, com ou sem Guattari, são inseridos dentro de seu projeto de criar uma filosofia da diferença e da crítica à ideia de representação. Daí a dispersão ou falta de uma sistematização e aprofundamento maior em algumas ideias, como Pelbart ${ }^{5}$, por exemplo, encontrou com relação à ideia de tempo, não obstante, seus vários elementos estarem interligados e formarem uma mesma concepção. Logo, não se trata de uma teoria do Estado elaborada por eles, nesses termos, mas de mostrar que eles não deixaram de operar certos deslocamentos nas leituras que fizeram, a fim de configurar sua leitura da história, especificamente das formações sociais, e, consequentemente, da ideia de Estado.

Segundo Dosse ${ }^{6}$, o conceito de máquina é central para fugir desses dois campos, uma vez que o compreendem enquanto expressão metonímica da máquina da sociedade industrial, além de ajudá-los na formulação de outra configuração da história. A ideia é que a máquina desejante se realiza por meio de agenciamentos, através das conexões que estes lhes possibilitam, a cada momento histórico, sendo integrada por linhas de fuga e devires moleculares. Inclusive, este autor sugere que a noção de "máquina desejante", usada para contrapor diretamente a psicanálise, depois é abandonada pelo conceito de agenciamento, especificamente de agenciamento maquínico ${ }^{7}$. De todo modo, trata-se de observar que sua "restituição da história da humanidade não se apresenta absolutamente como uma nova teleologia, na medida em que é animada pela contingência dos acontecimentos que faz com que os devires sociais se bifurquem em um ou outro sentido" ${ }^{\text {. }}$.

Isso é importante, por exemplo, quando consideramos as críticas que eles fazem as leituras que, por um lado, confundem "a irrupção do poder de guerra com a linhagem de dominação do Estado, [que é quando] tudo se embaralha, e a máquina de guerra passa a ser concebida unicamente sob a forma do negativo""; por outro, quando se concluem, acerca das

\footnotetext{
${ }^{4}$ MACHADO, Roberto. Deleuze e a filosofia. Rio de Janeiro: Graal, 1990.

${ }^{5}$ PELBART, Peter Pal. O tempo não-reconciliado. São Paulo: Perspectiva, 2015.

${ }^{6}$ DOSSE, François. Gilles Deleuze \& Félix Guattari: biografia cruzada. Trad. Fátima Murad; Rev. Técnica Maria Carolina dos Santos Rocha. Porto Alegre: Artmed, 2010.

${ }^{7}$ Ibidem., p. 111.

${ }^{8}$ Ibidem., p. 200.

${ }^{9}$ DELEUZE, Gilles; GUATTARI, Félix. Mil platôs: capitalismo e esquizofrenia 2. vol. 5. $2^{\mathrm{a}}$ ed. Trad. Peter Pál Pelbart e Janice Caiafa. São Paulo: Editora 34, 2012c, p. 16.
} 
sociedades ditas sem Estado, que elas "não atingiram o grau de desenvolvimento econômico, ou o nível de diferenciação política que tornariam a um só tempo possível e inevitável a

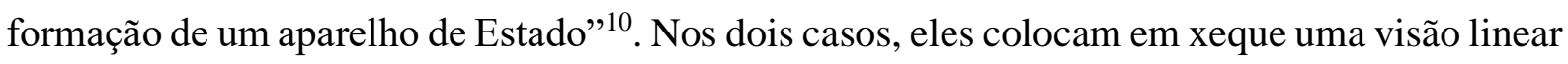
e evolucionista da história, sugerindo que, ao contrário, devemos restituir sua relação dinâmica e de exterioridade para acompanhar o processo que levou primeiro a constituição do Estado e, depois, da máquina capitalista moderna.

Dito de outro modo, o próprio exercício de pensar desses autores incorpora não só o caráter contingencial da história, como recoloca o desejo como elemento importante para a compreensão dos fluxos e dos agenciamentos que se operam em diferentes momentos ao longo do tempo. Nessa linha de pensamento, o caos e o devir emergem no pensamento desses autores antes como elementos que ajudam a refletir sobre as formações e organizações sociais, do que algo contra o qual se deve lutar no processo de produção do conhecimento. Ao contrário da história que, tendo surgido no seio do Estado, tende a operar cortes nos fluxos e devires, configurando-os de certa maneira num tempo cronológico e linear, que exclui o caos e o próprio desejo no processo de produção do saber histórico.

Com este intuito, em sua leitura da história da humanidade, Deleuze e Guattari ${ }^{11}$ destacam o funcionamento de três máquinas que explicam alguns dos processos sociais e históricos, sem deixar de considerar o devir, o heterogêneo e o caráter contingencial, como fazem outros pensadores da representação - que garantem o privilégio da identidade e de certa visão de história, enquanto pensamento nascido dentro do próprio Estado, portanto, também objeto de legitimação do poder -. Primeiro, temos a máquina territorial, ou dos selvagens, cujos destaques são feitos a partir da valorização da terra enquanto unidade produtiva, onde operam as codificações que marcam os espíritos e os corpos, fazendo o homem passar de um organismo biológico para um corpo pleno através do desenvolvimento de alianças laterais (política e econômica) e filiação (administrativa e hierárquica). Em seguida, a máquina estatal, ou imperial, faz a passagem dos selvagens aos bárbaros com um processo de sobrecodificação do corpo do déspota e de seu aparelho burocrático mediante o estabelecimento de alianças verticais, portanto de progressiva complexificação da sociedade, com várias novas segmentações e sedentarizações ${ }^{12}$. Por fim, a máquina capitalista civilizada, ou moderna, que

\footnotetext{
${ }^{10}$ Ibidem., p. 19.

${ }^{11}$ DELEUZE, Gilles; GUATTARI, Félix. $O$ anti-Édipo.

${ }^{12}$ Aqui a sobre codificação pode ser vista como o processo através do qual os códigos das sociedades primitivas são incorporados, ajustados e submetidos a nova inscrição imperial, notadamente ligada ao corpo do déspota, juntamente com o surgimento de novos problemas que, a exemplo das questões agrárias (fixação de residência) e da dívida (circulação do dinheiro versus dívida), são colocados de modo a afirmar o monopólio do Estado e sua
} 
decodifica e desterritorializa os fluxos do desejo, fazendo devir fluxos de dinheiro e produção, para, em seguida, axiomatizar ${ }^{13}$.

Essas três configurações evidenciam não só como os mesmos elementos podem entrar em agenciamentos distintos, seja estriando territórios, seja operando linhas de fuga, mas também o fato de que, ao longo da história, houve um processo acidental dos fluxos do desejo, que deveio uma sociedade mais aberta, como eram as primitivas, passando pelo endurecimento e tentativa de conter os fluxos, com o Estado, para, em seguida, ser canalizada para os interesses próprios da sociedade capitalista, conforme as operações próprias do capital. Então, o trabalho a se fazer é desenhar um mapa que nada mais é do que acompanhar essas linhas, especificamente três delas, conforme eles destacam: as que operam numa segmentaridade dita primitiva (tribos), caracterizada por ser relativamente flexível de códigos e de territorialidades entrelaçadas; as que implicam num aparelho de Estado (impérios) cuja linha é dura e tem uma forma de organização dual dos segmentos, a concentricidade dos círculos em ressonância e a sobrecodificação generalizada; por fim, as linhas de fuga (ou máquinas de guerra), que são marcadas por 'quanta' (aquilo que escapa aos centros de poder) e definidas por descodificação e desterritorialização ${ }^{14}$.

Entretanto, essas maneiras de organizar e apresentar sua leitura da história, ou mesmo a disposição dos volumes de seus livros, não pressupõem um antes e depois, pois todas elas são atravessadas por esses movimentos, coexistindo misturadas e transformando-se uma em outras. Podemos considerá-las, ainda, como estados simultâneos da Máquina abstrata: uma máquina abstrata de sobrecodificação que define uma segmentaridade dura, macro e que se reproduz binariamente, mas que não se confunde com o aparelho de Estado, apesar de remeter a ele; este último caso pode ser definido por uma máquina abstrata more geométrico, por ser um agenciamento de reterritorialização que efetua a máquina de sobrecodificação não se reduzindo nem a geometria nem a axiomática (condições ou limites) que cria; já no outro polo, uma máquina abstrata de mutação que opera por descodificação e desterritorialização traçando linhas de fuga e emitindo novos quanta.

própria preponderância na nova formação social e maquinações do desejo que emergem. Cf. DELEUZE, Gilles; GUATTARI, Félix. $O$ anti-Édipo.

${ }^{13}$ A ênfase dada a esse outro processo é que, diferente do Estado, o capitalismo não nasce de um golpe, mas surge sucessivamente, através da descodificação de vários fluxos, tais como os de dinheiro, propriedade, trabalho, etc., sendo progressivamente submetidos a uma axiomática social mais severa do que os antigos códigos, a saber, a axiomática do mercado capitalista mundial. Esta é pautada por uma mais-valia maquínica do capital e do homem (trabalho) que caracteriza tal sistema e o faz funcionar através de sua própria imanência - ao se colocar como objeto global de um investimento do desejo. Ibidem.

${ }^{14}$ DELEUZE, Gilles; GUATTARI, Félix. Mil Platôs: capitalismo e esquizofrenia 2. vol. 3. $2^{\mathrm{a}}$ ed. Trad. Aurélio Guerra Neto, Ana Lúcia de Oliveira, Lúcia Cláudia Leão e Suely Rolnik. São Paulo: Editora 34, 2012a, passim. 
A título de exemplo, usando os dois primeiros casos e retornando as formações sociais supracitadas, primeiro temos uma sociedade que pode ser caracterizada como relativamente flexível, por ser, ao mesmo tempo, “a [segmentaridade] de um código plurívoco, fundado em linhagens, suas situações e suas relações variáveis e a de uma territorialidade itinerante, fundada em divisões locais emaranhadas" ${ }^{\prime 15}$. Aqui não teríamos nem territórios, nem códigos fixos determinando sujeitos ou formações sociais, aliás, esse foi um dos motivos pelos quais os etnólogos sentiram necessidade não só de voltar o olhar para essas sociedades, mas de entender formações sociais que não tinham aparelhos centrais fixos, poder global ou instituições especializadas. Entretanto, no que diz respeito ao segundo caso, quando consideramos os Estados modernos, a diferença não está no fato de que eles são menos segmentários que os primeiros, mas que são mais endurecidos, de modo que o próprio Estado se exerce por segmentos - deixando passar ou mantendo os fluxos -, assim como ele mesmo possui sua própria segmentaridade e a impõe. Deste modo, teríamos não a oposição entre segmentário e centralizado, como alguns autores colocaram, mas dois tipos de segmentaridade, uma "primitiva" e flexível e outra "moderna" e dura, cujas distinções recorta as segmentaridades: binariamente, circularmente e linearmente ${ }^{16}$.

Sobre as oposições binárias, por exemplo, as de gênero ou de classes sociais, elas são fortes nas sociedades primitivas, mas resultam de máquinas e agenciamentos que não são binários, ao contrário das sociedades modernas que fazem valer máquinas duais que procedem por relações biunívocas e sucessivamente por escolhas binarizadas, simultaneamente ${ }^{17}$.

Quanto à forma circular, ela não implica que sejam concêntricos nos primeiros casos, de forma que seus centros procedem como "nós, olhos ou buracos negros", sem que impliquem a convergência para um mesmo ponto; por outro lado, nas sociedades com Estado, os círculos permanecem distintos, mas eles devêm concêntricos, são arborificados ${ }^{18}$. Ou seja, neste segundo exemplo, a diferença entre ambos é a concentricidade dos círculos distintos ou ressonância nos centros de poder, de maneira que "as sociedades com Estado se comportam

\footnotetext{
${ }^{15}$ Ibidem., p. 93.

${ }^{16}$ Ibidem., passim.

${ }^{17}$ DELEUZE, Gilles; GUATTARI, Félix. Mil Platôs: capitalismo e esquizofrenia 2. vol. 3.

${ }^{18}$ Ibidem., p. 95. A ideia de arborescência fica mais clara quando eles estão diferenciando o modelo de livro clássico do rizomático. O primeiro, a árvore é a imagem do mundo que deve ser imitado, caracterizando-se por procedimentos de reflexões e pela interioridade orgânica, significante e subjetiva. No segundo, a imagem do mundo, ou caosmo-rádicula, é aquela em que o uno se faz múltiplo, sem dimensão superior, cuja associação é feita com a haste subterrânea da botânica que se diferencia das raízes por ter formas e ramificações diversas, sem começo ou fim, que cresce no meio: "Um livro [que] existe apenas pelo fora e no fora". Cf. DELEUZE, Gilles; GUATTARI, Félix. Mil Platôs: capitalismo e esquizofrenia 2. vol. 1, p. 18. São, pois, dois modelos de pensamento que também são usados para diferenciar as formas de organização social, onde as sociedades primitivas inibem a organização da ressonância que emergem com o Estado, ou seja, inibem esses procedimentos de organização, permanecendo caracterizada pela multiplicidade.
} 
como aparelhos de ressonância, elas organizam a ressonância, enquanto que as primitivas as inibem"19.

Já no caso da segmentaridade linear, desde a cidade grega e a reforma de Clístenes aparece um espaço político homogêneo e isótopo, ou no caso do Império Romano, uma razão de Estado linear ou geométrica (planejamento territorial ou territorialidades do espaço). Entretanto, essa possível "geometria" (operatória) primitiva não separa as figuras de suas afecções, os segmentos de sua segmentação (há alinhamentos e arredondamentos, mas não linhas retas ou círculos), ao contrário da geometria ligada ao Estado que se manifesta pelo primado do elemento-teorema, substituindo as "formações morfológicas flexíveis por essências ideais ou fixas, afectos por propriedades, segmentações em ato por segmentos prédeterminados", entre todas as outras formas usadas para fixar e sedentarizar os elementos no corpo social ${ }^{20}$.

A forma como eles opõem uma espécie de segmentaridade arborificada e outra rizomática não indica só dois estados de um mesmo processo, mas evidencia também dois processos diferentes de como as sociedades primitivas procedem por códigos e territorialidades (sistema tribal ou de clãs de linhagens) que impedem a ressonância, na medida em que nas sociedades modernas ou com Estado os códigos desgastados são substituídos por uma sobrecodificação unívoca e as territorialidades perdidas são reterritorializadas de forma específica (espaço geométrico sobrecodificado). Em outras palavras, "A segmentaridade aparece sempre como resultado de uma máquina abstrata; mas não é a mesma máquina abstrata que opera no duro e no flexível"21. A despeito dessas diferenças, elas são inseparáveis, de modo que as primeiras possuem núcleos de dureza que tanto antecipam quanto conjuram o Estado; enquanto no segundo caso, os segmentos duros vingam por estarem banhados num tecido flexível.

Dito isso, os autores também ressaltam que tanto a sociedade quanto o indivíduo são atravessados por essas duas segmentaridades, coexistentes, que também podem ser definidas pelas categorias "molar" e "molecular" ou, ainda, pela "macropolítica" e "micropolítica". Para citar um de seus exemplos, o fascismo implica um regime molecular que inventou o conceito de Estado totalitário, que é uma macropolítica, de modo que há Estados totalitários de segmentaridade dura e com modo especial de totalização e centralização sem fascismo (por exemplo, as ditaduras militares ou estalinistas). O perigo deste último é exatamente sua atuação

\footnotetext{
${ }^{19}$ DELEUZE, Gilles; GUATTARI, Félix. Mil Platôs: capitalismo e esquizofrenia 2. vol. 3, p. 96.

${ }^{20}$ Ibidem., p. 97.

${ }^{21}$ DELEUZE, Gilles; GUATTARI, Félix. Mil Platôs: capitalismo e esquizofrenia 2. vol. 3, p. 98.
} 
micropolítica ou molecular, que pulula onde menos se espera e pode levar à pulsões de morte, tendo em vista que "o desejo nunca é separável de agenciamentos complexos que passam necessariamente por níveis moleculares, microformações que moldam de antemão as posturas, as atitudes, as percepções, as antecipações, as semióticas, etc."22. Além de uma outra ótica de história, temos também um comprometimento ético-político com as implicações de um conhecimento que pensa a diferença.

\section{CONCEPÇÃO DE ESTADO: ENTRE O MOLAR E O MOLECULAR}

A discussão que fizeram a partir de um pensamento da diferença fez com que os autores desenvolvessem não só uma leitura distinta da história da humanidade, como vimos, pensada em contraposição ao conhecimento calcado na ideia de representação, mas também teve ressonância em temáticas transversais que encontramos dispersas em suas obras, tal como sua concepção de Estado. Deste modo, não só este é pensado conceitualmente dentro de uma linha de pensamento que considera a multiplicidade e o fazer-se dos processos, como ele é localizado numa temporalidade histórica que significou uma primeira tentativa de conter os fluxos através de progressivas segmentações que, todavia, sempre contém a possibilidade de devir outro, porque algo sempre lhe escapa. Em linhas gerais, podemos dizer que "quanto mais a organização molar é forte, mais ela própria suscita uma molecularização de seus elementos, suas relações e seus aparelhos elementares”, o contrário também ocorre: "Quando a máquina devém planetária ou cósmica, os agenciamentos têm uma tendência cada vez maior a se miniaturizar e a devir microagenciamentos" 23 .

Nesse sentido, eles evidenciam como as linhas molares, comumente compreendidas em termos de estrutura, e as moleculares, associadas a toda uma cadeia de micropoderes, organizam e desorganizam diferentes territórios sociais, sem que uma sobressaia a outra, mas atuem tão somente em interações que caotizam o real, ou, tal como eles o definem: "O que é real é o próprio devir, o bloco de devir, e não os termos supostamente fixos pelos quais passaria aquele que devém" 24 . Aliás, é este um dos motivos pelos quais a preferência foi dada a ideia de máquina - como contendo diferentes e múltiplos agenciamentos - e não a de estrutura - com grandes significados e olhares macros -, porque é ela que possibilita acompanhar os devires, os movimentos e investimentos do desejo no campo social, enquanto o estruturalismo, além de não dar conta deles, ainda os denunciam como degradação ${ }^{25}$.

\footnotetext{
${ }^{22}$ Ibidem., p. 102.

${ }^{23}$ Ibidem., p. 102.

${ }^{24}$ DELEUZE, Gilles; GUATTARI, Félix. Mil Platôs: capitalismo e esquizofrenia 2. vol. 4. $2^{\mathrm{a}}$ ed. Trad. Suely Rolnik. São Paulo: Editora 34, 2012b, p. 18.

${ }^{25}$ Ibidem.
} 
Exemplificando do ponto de vista teórico esse pensamento, em oposição ao predomínio na sociologia de Durkheim que privilegia representações coletivas, eles contrapõem Gabriel Tarde, que propunha uma microssociologia atenta aos detalhes infinitesimais, "as pequenas imitações, oposições $e$ invenções, que constituem toda uma matéria sub-representativa", e segundo a qual o fluxo nada mais é do que um fluxo "de crença e de desejo"26, os dois aspectos de todo agenciamento e o fundo de toda sociedade, segundo os autores. Linha de segmentos e o fluxo de quanta são, pois, dois sistemas de referência estritamente complementares e coexistentes, que dizem respeito aos movimentos de decodificação e desterritorialização que animam um campo social, com velocidades e andamentos diferentes, na medida em que: "Um fluxo mutante implica sempre algo que tende a escapar aos códigos não sendo, pois, capturado, e a evadir-se dos códigos, quando capturado; e os quanta são precisamente signos ou graus de desterritorialização no fluxo descodificado"27.

Colocando em outros termos, na leitura do problema das massas ao longo dos séculos, temos que estas operam conexões desses fluxos de modo que um precipita os outros, produzindo sobrecodificações e reterritorializações, de tal forma que as representações ao definirem grandes segmentos sempre deixam escapar algo. Usando as proposições de Tarde, teríamos aí a propagação de um fluxo (imitação), a colocação deles em binaridade (oposição ou binarização) e a conjugação ou conexão de fluxos diversos (invenção). A diferença entre a conexão e a conjugação dos fluxos, é que a primeira marca a forma de decodificação e desterritorialização dos fluxos que são lançados uns pelos outros, fazendo precipitar sua fuga comum e seus quanta; no segundo caso, indica sua parada relativa que obstrui as linhas de fuga, operando uma reterritorialização geral, além de fazer passar fluxos capaz de sobrecodificá-los. Segundo os autores,

A tarefa do historiador é assinalar o "período" de coexistência ou de simultaneidade dos dois movimentos (de um lado, descodificaçãodesterritorialização e, de outro, sobrecodificação-reterritorialização). E é nesse período que se distingue o aspecto molecular do aspecto molar: de um lado as massas ou fluxos, com suas mutações, seus quanta de desterritorialização, suas conexões, suas precipitações; de outro lado, as classes ou segmentos, com sua organização binária, sua ressonância, sua conjugação ou acumulação, sua linha de sobrecodificação em proveito de uma delas. A diferença entre uma macro-história e uma micro-história não concerne de modo algum o tamanho das durações consideradas, o grande e o pequeno, mas sistemas de referências distintos, conforme se considere uma linha sobrecodificada de segmentos ou um fluxo mutante de quanta. E o

\footnotetext{
${ }^{26}$ Idem. Mil Platôs: capitalismo e esquizofrenia 2. vol. 3, p. 107, grifo dos autores.

${ }^{27}$ Ibidem., p. 108.
} 
sistema duro não detém o outro: o fluxo continua sob a linha, perpetuamente mutante, enquanto a linha totaliza ${ }^{28}$.

Desta feita, não se trata nem de contradição, nem de representação mas de agenciamentos e dinâmicas que perpassam os dois lados, a exemplo das distinções entre massa e classe, não são os mesmos contornos que os circundam, ainda que um grupo seja afetado pelos dois signos, a luta assume dois aspectos distintos, embora não haja menos relações de força e de violência de um para o outro lado. Os movimentos de massa - enquanto fluxos - se precipitam e se revezam, passam por mutações e emitem novos quanta que modificam as próprias relações de classe, questionando sua sobrecodificação e sua reterritorialização, fazendo passar em outros lugares as novas linhas de fuga.

Dito de outra forma, molar e molecular são duas formas de colocar questões que devem ser consideradas, por exemplo, na forma como trabalhamos as produções historográficas: no primeiro caso, o das formações sociais macroscópicas, consideram-se os grandes conjuntos molares ou máquinas sociais procurando saber "o que eles querem dizer" através de sua aplicação a um conjunto familiar, permanecendo no quadro da representação; no segundo, o das regiões de um inconsciente micrológico ou microfísico, ultrapassam-se esses conjuntos molares "em direção aos elementos moleculares que formam as peças e engrenagens das máquinas desejantes", procurando o modo como elas "funcionam", investindo e subdeterminando as máquinas sociais ${ }^{29}$. Há aqui toda uma crítica a concepção dos estruturalistas, no modo como olham a sociedade, por isso, como contraponto, sua proposta de esquizoanálise "parte do postulado de que o desejo não é de modo nenhum uma superestrutura, mas sim parte integrante do mundo da produção, do campo social que ele irriga em todos os pontos" $" 30$.

Ademais, como destacou Rolnik ${ }^{31}$, toda sociedade é investida de desejo e essas linhas delineiam todo e qualquer investimento do desejo no campo social, assim como este segue os movimentos de atualização de práticas e discursos sociais, não obstante sempre deixarem escapar afetos e linhas de fuga. Ora, a não dissociação entre desejo e campo social é importante também para entender como eles associam a psicanálise com o capitalismo, cuja principal crítica foi a redução da loucura ao complexo parental, resultante dessa associação. Inclusive, a família possui uma relação especial e diferencial tanto com o Estado quanto com as máquinas

\footnotetext{
${ }^{28}$ Ibidem., p. 110-111.

${ }^{29}$ DELEUZE, Gilles; GUATTARI, Félix. Mil Platôs: capitalismo e esquizofrenia 2. vol. 3, p. 242, grifo dos autores.

${ }^{30}$ DOSSE, François. Gilles Deleuze \& Félix Guattari, p. 172.

${ }^{31}$ ROLNIK, Suely. Cartografia Sentimental: transformações contemporâneas do desejo. $2^{\mathrm{a}}$ ed. Porto Alegre: Sulina; Editora da UFRGS, 2016.
} 
de guerra nos deslocamentos que operam nas leituras, fazendo com que mesmo no primeiro caso haja a ação de outros elementos que imprimem uma dinâmica singular na organização do corpo social ${ }^{32}$.

Deste modo, é primordial compreender, dentro da crítica feita por Deleuze e Guattari ${ }^{33}$ ao estruturalismo e a psicanálise, que não se trata apenas de reconhecer que existem estruturas, mas também que essa demarcação não depende de análises que impliquem universais ou psicologismos, como sugere a ideia de Édipo sob a ótica parental ${ }^{34}$, ou apenas uma imitação do múltiplo, conforme o pensamento da identidade; mas sim de acompanhar as composições de multiplicidades ou os conjuntos de intensidades, que enquanto rizomas podem servir a novos e estranhos usos, pois o pensamento em si não responde a hierarquias ou funciona a partir da hegemonia do significante ${ }^{35}$. Ainda que isso não signifique ignorar ou opor uma lógica macro e outra micro, um pensamento arborescente a outro de raiz, pois ambos "não se opõem como dois modelos: um age como modelo e como decalque transcendentes, mesmo que engendre suas próprias fugas; o outro age como processo imanente que reverte o modelo e esboça um mapa, mesmo que constitua suas próprias hierarquias" 36 .

Essa é a teoria a partir da qual o Estado é pensado, mediante agenciamento de autores e obras, não somente em seu aspecto macro, mas também considerando o micro, o que opera toda uma nova leitura na forma de concebê-lo. Por exemplo, partindo de algumas teses de Clastres, eles o definem pela "perpetuação ou conservação de órgãos de poder" ${ }^{\text {37 }}$ e enfatizam o fato de

\footnotetext{
${ }^{32}$ DELEUZE, Gilles; GUATTARI, Félix. Mil platôs: capitalismo e esquizofrenia 2. vol. 5.

${ }^{33}$ Idem. $O$ anti-Édipo.

${ }^{34}$ Reformulam a leitura feita de Édipo na psicanálise, através da interpretação histórica citada anteriormente, cabe salientar inclusive que tanto essa crítica quanto a feita aos estruturalistas, estão inseridas na sua forma de pensar a diferença. Por exemplo, num dos tópicos do livro O Anti-Édipo, eles especificam em que sentido Édipo é universal, partindo de sua ideia de que a produção desejante está no limite e que este possui vários sentidos, conforme apresentamos aqui na sequência: 1) limite absoluto: quando ela está no limite da produção social, quando os fluxos descodificados estão no limite dos códigos e territorialidades, por exemplo, a esquizofrenia faz os esquizo-fluxos passarem através do muro e desterritorializar o socius; 2) limite relativo: é quando se faz correr fluxos descodificados, mas substituindo os códigos por uma axiomática mais opressora, como na formação social capitalista que não para de aproximar-se do muro e afastá-lo ao mesmo tempo; 3 ) limite real: é o limite reprimido de dentro de uma sociedade, pois esta ao pressentir o risco da destruição de seus códigos, esconjura-no, e olhamno com melancolia quando ele revém de fora trazendo o signo de sua morte, tais quais os impedimentos colocados nas formações anteriores aos fluxos de dinheiro e produção; 4) limite imaginário: é aquele que projeta num começo primordial este limite inibido no interior, como no caso da matriz mítica que imagina os fluxos não codificados invadindo o socius e introduzindo a desordem no mundo; 5) limite deslocado: que consiste em fazer com que o limite passe para o interior ou meio do socius, operando seu deslocamento para esconjurar suas forças, tal como faz Édipo, fazendo do limite um além da aliança e aquém da filiação, um entre dessas duas representações. É nesse último sentido que Édipo é universal, como limite deslocado, como "o representado deslocado que desfigura o que todas as sociedades temem absolutamente como seu mais profundo negativo, a saber, os fluxos descodificados do desejo". Ibidem., p. 234. Em outras palavras, Édipo só é produzido “como resultado de uma história que põe em jogo o devir das máquinas sociais e seu regime em comparação com o das máquinas desejantes”. Ibidem., p. 243.

${ }_{35}$ Idem. Mil Platôs: capitalismo e esquizofrenia 2. vol. 1.

${ }^{36}$ Ibidem., p. 42.

${ }^{37}$ DELEUZE, Gilles; GUATTARI, Félix. Mil platôs: capitalismo e esquizofrenia 2. vol. 5, p. 19.
} 
que, ao contrário do que muitos acreditavam, as sociedades primitivas tiveram sempre a preocupação em conjurar sua formação, através de vários mecanismos criados contra a concentração de poder, e não eram simplesmente sistemas menos desenvolvidos:

Conjurar a formação de um aparelho de Estado, tornar impossível uma tal formação, tal seria o objeto de um certo número de mecanismos sociais primitivos, ainda que deles não se tenha uma consciência clara. Sem dúvida, as sociedades primitivas possuem chefes. Mas o Estado não se define pela existência de chefes, e sim pela perpetuação ou conservação de órgãos de poder. A preocupação do Estado é conservar. Portanto, são necessárias instituições especiais para que um chefe possa devir homem de Estado, porém requer-se não menos mecanismos difusos para impedir que isso ocorra. Os mecanismos conjuratórios ou preventivos fazem parte da chefia, e a impedem que se cristalize num aparelho distinto do próprio corpo social. Clastres descreve essa situação do chefe cuja única arma instituída é seu prestígio, cujo único meio é a persuasão, cuja única regra é o pressentimento dos desejos do grupo [...]. E mais: Clastres considera que, nas sociedades primitivas, a guerra é o mecanismo mais seguro contra a formação do Estado: é que a guerra mantém a dispersão e a segmentaridade dos grupos, e o guerreiro é ele mesmo tomado num processo de acumulação de suas façanhas que o conduz a uma solidão e a uma morte prestigiosas, porém sem poder ${ }^{38}$.

A importância dada a essa tese de esconjuração do Estado pelas sociedades primitivas está no fato de colocar em evidência a existência de mecanismos coletivos de inibição, que não só quebra com uma visão linear e evolucionista da história, como evidenciam a formação de um tecido de relações imanentes, cujas características contingentes e de difusão colocam em questão toda uma construção narrativa da história centrada em referências ligadas aos centros de poder, como se apresentam em grupos ou estruturas sociais.

Todavia, não há somente concordância com as teses de Clastres, mas também críticas, pois este, segundo os autores, se por um lado deu elementos para se pensar o triunfo do Estado, por outro, privou-se do meio de resolvê-los, ao aprofundar a clivagem entre Estado e máquina de guerra, permanecendo numa linha de pensamento evolucionista ${ }^{39}$. Em razão disso, além do fato de acreditarem na hipótese de que Urstaat sempre existiu, eles preferem chamar a atenção para "a hipótese inversa: que o Estado ele mesmo sempre esteve em relação com um fora, e não é pensável independentemente dessa relação" ${ }^{40}$. Deslocando, deste modo, a discussão que aquele autor fazia acerca das sociedades com ou sem Estados, para as relações de interioridade (forma-Estado) e exterioridade (máquina de guerra):

Não apenas não há Estado universal, mas o fora dos Estados não se deixa reduzir à "política externa", isto é, a um conjunto de relações entre Estados. $\mathrm{O}$ fora aparece simultaneamente em duas direções: grandes máquinas

\footnotetext{
${ }^{38}$ Ibidem., p. 19-20, grifo dos autores.

${ }^{39}$ DELEUZE, Gilles; GUATTARI, Félix. Mil platôs: capitalismo e esquizofrenia 2. vol. 5, p. 22-23.

${ }^{40}$ Ibidem., p. 24.
} 
mundiais, ramificadas sobre todo o ecúmeno num momento dado, e que gozam de uma ampla autonomia com relação aos Estados [...]; mas também mecanismos locais de bandos, margens, minorias, que continuam a afirmar os direitos de sociedades segmentárias contra os órgãos de poder de Estado [...]. O que é evidente é que bandos, não menos que as organizações mundiais, implicam uma forma irredutível ao Estado, e que essa forma de exterioridade se apresenta necessariamente como a de uma máquina de guerra, polimorfa e difusa $^{41}$.

Essas relações pressupõem tanto uma coexistência e concorrência de ambos os elementos, quanto um campo de perpétua interação entre as máquinas de metamorfose e os aparelhos identitários do Estado. Por consequência, o que podemos sintetizar das ideias anteriores, é que as sociedades primitivas não só possuíam elementos que antecipavam o Estado, como este ao surgir se apropriou de certos arcaísmos para formar uma configuração distinta. Como eles exemplificam através dos fenômenos de bandos ou maltas, e até mesmo do banditismo, esses mecanismos formam teias de relações que, funcionando como linhas de fuga podem, inclusive, fazer ruir ou criar frestas nas organizações mais sólidas. Acompanhar esse raciocínio por si só, já evidenciam toda uma gama de agenciamentos que a ideia de estrutura desconsidera, ao insistir com um olhar macro, ou pensamento arborescente. E, mais do que isso, não significa de nenhum modo desconsiderar essa forma de olhar, mas entender que de fato ela é uma das maneiras possíveis.

É baseado num outro pensamento fasciculado que Deleuze e Guattari ${ }^{42}$ defendem a ideia de que a máquina de guerra é irredutível ao aparelho de Estado, entre outros motivos, porque este não inclui a guerra, enquanto aquele, embora não tenha a guerra por objeto, possui sua potência:

Ou bem o Estado dispõe de uma violência que não passa pela guerra: ele emprega policiais e carcereiros de preferência a guerreiros, não tem armas e delas não necessita, age por captura mágica imediata, "agarra" e "liga", impedindo qualquer combate. Ou então o Estado adquire um exército, mas que pressupõe uma integração jurídica da guerra e a organização de uma função militar. Quanto à máquina de guerra em si mesma, parece efetivamente irredutível ao aparelho de Estado, exterior a sua soberania, anterior a seu direito: ela vem de outra parte ${ }^{43}$.

Ainda que possa haver alguma confusão entre elas, o principal é que o Estado é ligação, especificamente, um aparelho de captura, enquanto a máquina de guerra, com sua natureza distinta, considera o devir e, por isso, tem uma potência contra a soberania: “O Estado é a soberania. No entanto, a soberania só reina sobre aquilo que ela é capaz de interiorizar, de

\footnotetext{
${ }^{41}$ Ibidem., p. 25, grifo dos autores.

42 Ibidem.

${ }^{43}$ DELEUZE, Gilles; GUATTARI, Félix. Mil platôs: capitalismo e esquizofrenia 2. vol. 5, p. 12-13, grifo dos autores.
} 
apropriar-se localmente" ${ }^{\not 4}$. Possuindo uma relação variável com a guerra, seu objeto é o traçado de linhas de fuga criadoras contra o próprio aparelho de Estado, esconjurando suas tentativas de captura, o qual "não se concebe sem uma relação com um de fora do qual se nutre, enquanto a máquina de guerra vive um agenciamento social cujo modelo matricial é o nomadismo" 45 .

No modo como estruturam sua explanação, eles operam contraposições entre estruturas dos tipos rizomáticos e as arborescentes. Em geral, os órgãos de poder são definidos como esse segundo caso, enquanto os bandos ou maltas, incluindo a "bandidagem", são grupos tidos como rizomáticos. Por exemplo, eles sugerem que a desconfiança do Estado com relação às instituições militares deriva do fato desta proceder como máquina de guerra, daí a preferência pela criação de aparelhos burocráticos ou administrativos, como são os casos das polícias criadas durante o processo de formação dos Estados Modernos. Aliás, esse é um dos motivos pelos quais acreditamos que eles deram mais atenção aos primeiros e não aos segundos, já que estavam mais preocupados em evidenciar como algumas características decorrentes da captura pelo aparelho do Estado, por exemplo, o fato de que "a disciplina devém a característica obrigatória dos exércitos quando o Estado se apodera deles" ${ }^{\prime 4}$.

Por conseguinte, eles acreditam que o Estado surgiu de um golpe, como acontecimento puro, apesar de toda a luta das sociedades primitivas contra ele, empregando suas máquinas de guerra e tentando manter a segmentaridade dos grupos. Ele formou grandes corpos, entendidos como "organismos diferenciados e hierarquizados que, de um lado, dispõem do monopólio de um poder ou de uma função; de outro, repartem localmente seus representantes" ${ }^{\prime 4}$. Ao invés de usarem, como os marxistas, a ideia de modo de produção, eles preferiram definir as formações sociais como processos maquínicos, posto que lhes "Parece evidente que o Estado surge de uma só vez, sob uma forma imperial, e não remete a fatores progressivos" 48 . Como enfatizou Dosse:

Distinguem a propósito disso as sociedades primitivas cujos mecanismos de funcionamento são os da conjuração-antecipação, as sociedades com Estado definidas por seus instrumentos de polarização, as sociedades nômades por suas máquinas de guerra. Enquanto o Estado se empenha em capitalizar, em se apropriar, a máquina de guerra tem uma potência de metamorfose [...]. Essa propensão à captura e à sobrecodificação do aparelho de Estado coloca o problema das minorias, que devem ser capazes de constituir máquinas de guerra para evitar seu desaparecimento ${ }^{49}$.

\footnotetext{
${ }^{44}$ Ibidem., p. 24.

${ }^{45}$ DOSSE, François. Gilles Deleuze \& Félix Guattari, p. 215.

${ }^{46}$ DELEUZE, Gilles; GUATTARI, Félix. Mil platôs: capitalismo e esquizofrenia 2. vol. 5, p. 22.

${ }^{47}$ Ibidem., p. 33.

${ }^{48}$ Ibidem., p. 22.

${ }^{49}$ DOSSE, François. Gilles Deleuze \& Félix Guattari, p. 218, grifo do autor.
} 
Por isso, segundo este autor, eles colocaram todo esse problema como político e a necessidade de preservar as micropolíticas plurais e resistentes, bem como cartografar seus elementos ${ }^{50}$, revelando também toda uma dimensão ética, sobretudo, quando enfatizam que todo devir é minoritário e existe a possibilidade de operar agenciamentos que produzam algo diferente socialmente: "os corpos coletivos sempre têm franjas ou minorias que reconstituem equivalentes de máquina de guerra, sob formas por vezes muito inesperadas, em agenciamentos determinados" ${ }^{21}$. Sem confundir esses agenciamentos com organizações como instituição familiar ou com o aparelho de Estado, mas colocando em termos de diferença de natureza, eles evidenciam que "a origem das matilhas é totalmente outra que a das famílias e dos Estados e ela não para de trabalhá-las por baixo, de perturbá-las de fora, com outras formas de conteúdo, outras formas de expressão", logo novos territórios possíveis de existência ${ }^{52}$.

Destarte, entre suas principais características, os agenciamentos maquínicos, ao contrário do Estado, não possuem propriedades intrínsecas, não são subjetivados, codificam ou estriam o espaço, mas sim percorrem espaços lisos, territorializando e desterritorializando. Dito de outro modo, a máquina de guerra é pura forma de exterioridade: "ao passo que o aparelho de Estado constitui a forma de interioridade que tomamos habitualmente por modelo, ou segundo a qual temos o hábito de pensar" ${ }^{, 53}$. Por essa razão, a cartografia passa por uma ciência nômade (ou nomadologia), e não pela história, uma vez que esta não se preocupa em seguir fluxos, ao contrário dos modelos de devir, de heterogeneidade, turbilhonares e problemáticos, sugeridos por Michel Serres, que opera várias modificações do olhar:

O modelo é turbilhonar, num espaço aberto onde às coisas-fluxo se distribuem, em vez de distribuir um espaço fechado para coisas lineares e sólidas. É a diferença entre espaço liso (vetorial, projetivo ou topológico) e um espaço estriado (métrico): num caso, "ocupa-se o espaço sem media-lo", no outro, "mede-se o espaço a fim de ocupá-lo". 4) Por último, o modelo é problemático, e não mais teoremático: as figuras só são consideradas em função das afecções que lhes acontecem, secções, ablações, adjunções, projeções. Não se vai de um gênero a suas espécies por diferenças específicas, nem de uma essência estável às propriedades que dela decorrem por dedução, mas de um problema aos acidentes que o condicionam e o resolvem ${ }^{54}$.

Falar em modelo problemático é compreender que a própria escrita requer um comprometimento com o pensamento da diferença, o qual considera os agenciamentos operados nesse processo e a existência de uma ciência vaga ou nômade que é irredutível aos

\footnotetext{
${ }^{50}$ DOSSE, François. Gilles Deleuze \& Félix Guattari.

${ }^{51}$ DELEUZE, Gilles; GUATTARI, Félix. Mil platôs: capitalismo e esquizofrenia 2. vol. 5, p. 34.

${ }^{52}$ Idem. Mil Platôs: capitalismo e esquizofrenia 2. vol. 1, p. 24.

${ }^{53}$ Idem. Mil platôs: capitalismo e esquizofrenia 2. vol. 5, p. 15-16.

${ }^{54}$ Ibidem., p. 26, grifo dos autores.
} 
homens de Estado, inclusive: "Poderia dizer-se que a máquina de guerra se projeta num saber abstrato, formalmente diferente daquele que duplica o aparelho do Estado"55. E esse modelo de ciência assume outras relações com os elementos que constituem seu trabalho. Desta feita, mais do que projetar teorias sobre o que está sendo estudado, assumir um pensamento rizomático significa poder "deslocar-se fora das estriagens do "espaço mental" imposto pelas imagens clássicas do pensamento e seus modelos", tal como são provenientes do próprio Estado ${ }^{56}$.

Por isso que, dentre outras coisas, Pelbart enfatiza que pensar a diferença é, sobretudo, pensar o tempo a partir do meio, a partir de uma lógica da multiplicidade ou rizomática, que entende que não há reconciliação entre passado, presente e futuro em direção a um sentido pressuposto desde o início, mas tão somente um emaranhado, de onde se pode entrar e sair de qualquer ponto, pois o rizoma: "é feito de direções móveis, sem início ou fim, mas apenas um meio, por onde ele cresce e transborda; um rizoma não remete a uma unidade nem dela deriva; não tem sujeito nem objeto" ${ }^{" 57}$. O que está em jogo, em outras palavras, é destituir o privilégio dado a verdade e restituir a potência do falso, e, do ponto de vista da ideia de estrutura, trata-se de evidenciar que por si só, ela não tem forma, significação, conteúdo ou realidade empírica, mas tão somente elementos coexistentes "num espaço topológico, inextenso, pré-extensivo"; trata-se, enfim, de assumir sua multiplicidade, das ligações não-localizáveis entre seus elementos diferenciais, ou sua virtualidade ${ }^{58}$.

Sem entrar na discussão feita por Pelbart ${ }^{59}$ acerca do intempestivo em Nietzsche, o importante é entender de que forma podemos pensar a história nesses termos, ou seja, como a assunção dessa tarefa criadora e destruidora pode contribuir para outra forma de trabalhar neste campo. Usando o exemplo da crítica direcionada a filosofia, podemos sugerir que a ideia é desfazer-se do universal e do abstrato, bem como considerar as forças que fazem o pensamento. Só então teremos condições de levar mais longe os questionamentos de valores e das verdades da ordem estabelecida, mesmo tratando-se de uma ciência surgida com o Estado e que também trabalha estriando o plano social. Pois, se, por um lado, o principal problema colocado pela teoria da multiplicidade dos autores à história é a questão de como ela pode trabalhar acompanhando essas inscrições tendo sido criada a partir de um aparelho de Estado para operar cortes; por outro lado, eles sinalizam uma possibilidade de agir acompanhando não os indivíduos, mas as conexões e disjunções, os investimentos do desejo no corpo social a cada

\footnotetext{
55 Ibidem., p. 27.

${ }^{56}$ PELBART, Peter Pal. O tempo não-reconciliado, p. 30.

${ }^{57}$ PELBART, Peter Pal. O tempo não-reconciliado, p. XX.

58 Ibidem., p. 42.

${ }^{59}$ Ibidem.
} 
período, como o fez Rolnik ${ }^{60}$ acerca da cartografia dos desejos no Brasil, na segunda metade do século XX, sem dissociar produção social da desejante.

Existem vários direcionamentos ou indicações de como a história pode servir a outros fins que não o fortalecimento da doxa ou da imagem do pensamento dominante, notadamente quando voltar seu olhar para os distintos agenciamentos do desejo e produção de novos territórios. Ainda mais quando consideramos que os investimentos sociais do desejo a cada momento histórico tenderam a codificar, sobrecodificar ou descodificar os fluxos, mas sempre com o objetivo de que eles não ficassem tão livres, pois mesmo a liberação proporcionada pelo capitalismo não o foi sem um direcionamento de suas forças - inclusive eles evidenciaram como essa última formação foi a que mais segmentou o sujeito, produzindo esquizos ${ }^{61}$. Não obstante, salientaram também o fato de que nós não conseguimos viver totalmente desterritorializados, já que quando esses fluxos não são capturados ou territorializados, tendem a se destruir; além de que o próprio socius é fruto - e existe por causa - dessas capturas.

Assim, aceitar o exercício de pensar as fontes no fora e pelo fora significa dar outro sentido para a história, agora considerando o rizoma e acompanhando os diferentes agenciamentos maquínicos, os quais passam por linhas e intensidades, ou multiplicidades, e delineiam a experiência humana, inclusive a do próprio historiador. Principalmente se considerarmos a definição de agenciamento, em tudo o que ela pode dizer respeito aos nossos objetos e narrativas, enquanto "todo conjunto de singularidades e de traços extraídos do fluxo - selecionados, organizados, estratificados - de maneira a convergir (consistência) artificialmente e naturalmente: um agenciamento, nesse sentido, é uma verdadeira invenção"62.

\section{CONSIDERAÇÕES FINAIS}

Á guisa de conclusão, devemos repensar o modo como produzimos passado, sobretudo a maneira como nos utilizamos dos conceitos para encadear nossa narrativa. A opção por agenciar aqueles que são colocados por nossas fontes em função da questão que trabalhamos, pode resultar numa outra configuração da narrativa historiográfica que não aquela que apenas opera uma síntese para melhor explicar. Observar os agenciamentos coletivos de enunciação e o modo como funcionam na documentação é um dos caminhos a ser seguido para que haja produção de tramas cada vez mais rizomáticas, mostrando "até que ponto do rizoma se formam fenômenos de massificação, de burocracia, de leadership, de fascistização, etc., que linhas subsistem, no entanto, mesmo subterrâneas, continuando a fazer obscuramente rizoma", pois

\footnotetext{
${ }^{60}$ ROLNIK, Suely. Cartografia Sentimental.

${ }^{61}$ DELEUZE, Gilles; GUATTARI, Félix. Mil Platôs: capitalismo e esquizofrenia 2. vol. 3.

${ }^{62}$ Idem. Mil platôs: capitalismo e esquizofrenia 2. vol. 5, p. 94.
} 
mesmo "um acontecimento microscópio estremece o equilíbrio do poder local" ${ }^{63}$. Essa ambiguidade mesma, ou multiplicidade, foi o que os levou a toda a questão de compreender como o sujeito foi sendo construído socialmente, como a sociedade se organizou e o arranjou de uma forma diferente a cada nova estratificação; bem como, resultou na percepção do modo de funcionamento do Estado Moderno, o qual tendeu a segmentar cada vez mais o sujeito e a complexificar a sociedade com uma gestão segmentária progressiva. Mesmo que nada impedisse que algo se instalasse na passagem de um segmento a outro.

A proposta de fazer esquizoanálise ou micropolítica, considerar antes uma Nomadologia, ao contrário da história feita por sedentários e em nome do aparelho do Estado, é entender esses agenciamentos ligados ao fora que produzem multiplicidades, assim como os movimentos de captura pelo aparelho do Estado, considerando que este "foi o modelo do livro e do pensamento: o logos", assim como foi e é sua pretensão "ser imagem interiorizada de uma ordem do mundo e enraizar o homem" ${ }^{64}$. Ratificando, deste modo, a necessidade de fazer acompanhar todos os tipos de devires, assim como os agenciamentos maquínicos de desejo ou os agenciamentos coletivos de enunciação que em suas multiplicidades operam sobre os fluxos e põem em jogo várias conexões e novas produções

Assim, se na primeira parte desse texto vimos uma leitura da história da humanidade com a qual não estamos acostumados, uma vez que nossa própria tradição é de pensar a representação e não a diferença; na segunda, foi possível vislumbrar algumas possibilidades de pensar as maquinações do desejo e os agenciamentos que conformam as organizações sociais e o próprio Estado. Desta feita, a leitura de tais textos e as reflexões que foram suscitadas por eles configuram-se como um convite ao historiador - e demais pesquisadores interessados nos fluxos e devires dos processos sociais - para a assunção do caráter contigencial e do vir-a-ser das formações sociais, da observação dos fluxos que passam tanto pelas codificações das sociedades ditas primitivas e sobrecodificações das sociedades autodenominadas modernas, quanto pelas descodificações da sociedade capitalista mundial. E, mais do que isso, funcionaram como um alerta ao nosso modo de pensar e produzir conhecimento, ao sugerir que já não basta olhar somente para o macro ou enfatizar apenas o caráter múltiplo do micro, mas sim as temporalidades e os processos históricos que fazem com que a todo momento os dois se articulem e formem emaranhados e rizomas. Mesmo com a ressalva de que a história sempre chega depois que o devir já passou, e que este seja o que não é capturado por ela.

\footnotetext{
${ }^{63}$ Idem. Mil Platôs: capitalismo e esquizofrenia 2. vol. 1, p. 33 e 34.

${ }^{64}$ Ibidem., p. 48.
} 


\section{Recebido em: 23/03/2018}

\section{Aceito em: 10/05/2018}

\section{REFERÊNCIAS BIBLIOGRÁFICAS}

DELEUZE, Gilles; GUATTARI, Félix. O que é filosofia? Trad. Bento Prado Jr. e Alberto Alonso Muñoz. Rio de Janeiro: Ed. 34, 1992.

Kafka: por uma literatura menor. Trad. Rafael Godinho. Rio de Janeiro: Assírio \& Alvim, 2003.

O anti-Édipo: capitalismo e esquizofrenia $1.2^{\mathrm{a}}$ ed. Trad. Luiz B. L. Orlandi. São Paulo: Editora 34, 2011a.

. Mil Platôs: capitalismo e esquizofrenia 2. vol. 1. $2^{\mathrm{a}}$ ed. Trad. Ana Lúcia de Oliveira, Aurélio Guerra Neto e Celia Pinto Costa. São Paulo: Editora 34, 2011 b.

Mil Platôs: capitalismo e esquizofrenia 2. vol. 3. $2^{\mathrm{a}}$ ed. Trad. Aurélio Guerra Neto, Ana Lúcia de Oliveira, Lúcia Cláudia Leão e Suely Rolnik. São Paulo: Editora 34, 2012a.

Mil Platôs: capitalismo e esquizofrenia 2. vol. 4. $2^{\mathrm{a}}$ ed. Trad. Suely Rolnik. São Paulo: Editora 34, 2012b.

Mil platôs: capitalismo e esquizofrenia 2. vol. 5. $2^{\mathrm{a}}$ ed. Trad. Peter Pál Pelbart e Janice Caiafa. São Paulo: Editora 34, 2012c.

DOSSE, François. Gilles Deleuze \& Félix Guattari: biografia cruzada. Trad. Fátima Murad; Rev. Técnica Maria Carolina dos Santos Rocha. Porto Alegre: Artmed, 2010.

MACHADO, Roberto. Deleuze e a filosofia. Rio de Janeiro: Graal, 1990.

PELBART, Peter Pal. O tempo não-reconciliado. São Paulo: Perspectiva, 2015.

ROLNIK, Suely. Cartografia Sentimental: transformações contemporâneas do desejo. $2^{a}$ ed. Porto Alegre: Sulina; Editora da UFRGS, 2016. 